\author{
Contato \\ Instituto de História - UFR \\ Largo de São Francisco de Paula, $\mathrm{n}^{\circ} 1$ \\ 20.050-070 - Rio de Janeiro - R \\ gabrielcgc@terra.com.br
}

\section{A POUSSEMIA (SOCIAL) DO DESERTO: UMA HISTÓRIA DO TÓPOS HISTÓRICO E HISTORIOGRÁFICO DA SOLDÃO MONÁSTICA NO CONTEXTO LATINO MEDIEVAL}

\author{
Gabriel de C. G. Castanho**
}

Universidade Federal do Rio de Janeiro Rio de Janeiro - Rio de Janeiro - Brasil

\title{
Resumo
}

O presente artigo visa demonstrar que a visão historiográfica tradicional a respeito da solidão medieval é tributária da revalorização de alguns lugares comuns da retórica clássica e bíblica empregados pela documentação do período. Constatação não sem importância, uma vez que ela nos abre um novo horizonte analítico ainda não explorado pelos estudos monásticos: a função social da solidão medieval. Metodologicamente, o texto propõe o exame de relações lexicais dinâmicas presentes no campo semântico da solidão medieval. Ao final de nosso percurso teremos demonstrado que o deserto latino deve ser compreendido em função do processo de transferência da noção oriental para o ocidente. Uma transferência que coloca a solidão sob o controle de especialistas do isolamento cristão, tais como eremitas e monges. Esses reivindicam para si o monopólio da ocupação de um espaço de solidão: o eremus. Defende-se, assim, que a noção latinizada de solidão, bem como a polissemia do desertum bíblico, implica uma concepção "territorializada" do espaço na medida em que os agentes sociais em questão pretendem exercer sua influência de forma exclusiva sobre este espaço.

\section{Palavras-chave}

Solidão - Idade Média - semântica histórica.

A presente pesquisa foi realizada com financiamento da Capes por meio de uma bolsa de doutorado pleno desenvolvido na Universidade de Paris 1 e na EHESS (Paris) entre os anos de 2009 e 2013.

** Doutor em História e Civilizações pela École des Hautes Études en Sciences Sociales - Paris. Professor adjunto do Instituto de História e do Programa de Pós-Graduação em História Social da Universidade Federal do Rio de Janeiro. 


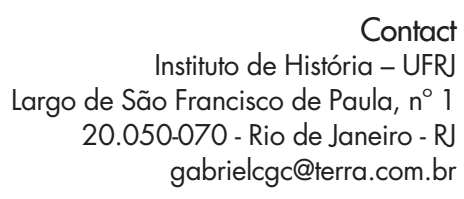

Contact

Instituto de História - UFR

Largo de São Francisco de Paula, $n^{\circ} 1$

20.050-070 - Rio de Janeiro - R

gabrielcgc@terra.com.br

\section{THE (SOCIAL)}

POLYSEMY OF THE

DESERT: A HISTORY

OF HISTORICAL AND

HISTORIOGRAPHICAL

TOPOS OF THE

MONASTIC SOLITUDE

IN MEDIEVAL LATIN

\section{CONTEXT}

\author{
Gabriel de C. G. Castanho* \\ Universidade Federal do Rio de Janeiro \\ Rio de Janeiro - Rio de Janeiro - Brazil
}

\begin{abstract}
This paper aims to demonstrate that the traditional historiographical vision of the medieval solitudo is a consequence of the revaluation of some common places of the classical and biblical rhetoric during the period. This is an important observation as it leds us to a new analytical horizon not explored by the monastic studies yet: the social function of the medieval solitude. In methodological terms, this article proposes the exam of the dynamic lexical relations present in the semantic field of the medieval solitude. At the end of our exposition we will have demonstrated that the Latin desert must be understood in relation with the transfer process of the oriental notion to the west. A transfer that brings the solitude under control of some Christian specialists in isolation, such as hermits and monks. These characters claim for themselves the monopoly on the occupation of the space of solitude: the eremus. In the end, this essay argues that the Latinized solitude notion, as well as the polysemy of the biblical desertum, implicate a "territorialized" conception of the space, as the social agents involved intend to exercise their influence (in an exclusive form) on this space.
\end{abstract}

\title{
Keywords
}

Solitude - Middle Ages - historical semantics. 


\section{Introdução}

Para o historiador, a solidão é antes de tudo uma palavra, um termo, um campo semântico presente na documentação por ele estudada. A afirmação pode parecer evidente, uma vez que, durante séculos, o texto escrito foi tido como sendo a matéria prima, e quase única, dos estudos históricos. Por outro lado, destacar o aspecto verbal da solidão abre as portas para a desconstrução da aparente autonomia universalizante deste conceito que, para muitos pensadores, seria um fato humano atemporal, cabendo ao historiador estabelecer a genealogia ou a tipologia das formas de solidão existentes ao longo da história. ${ }^{1}$ Assim, o estudo atento à polissemia da solidão, buscando aprofundar a compreensão histórica e social do objeto em questão, abordará os processos de construção da solidão praticada por uma dada sociedade em um determinado tempo.

No presente artigo, pretendo analisar o estabelecimento da noção cristã de solidão a partir de dois aspectos principais: o texto bíblico e seu legado retórico reutilizado por autores medievais (e também por alguns historiadores, literatos e arqueólogos contemporâneos) que trataram das fundações monásticas no deserto. Grosso modo, a criação de novos mosteiros muitas vezes está calcada em relatos histórico-hagiográficos que narram a chegada de um homem religioso a um local inóspito para ali viver como eremita. Ao longo dos anos, o homem sofreria as mais duras provações, mas nunca abandonaria sua fé, testemunho de sua beatitude ou de sua santidade inata que acabaria por atrair seguidores, dando assim origem a uma casa monástica. Sem esmiuçar aqui os benefícios obtidos ao se constituir semelhante narrativa de fundação (como, por exemplo, garantir para a comunidade monástica o controle sobre a terra e os homens dependentes do mosteiro por meio da santa autoridade de que são herdeiros), é interessante destacar que os debates a respeito do isolamento original reivindicado por mosteiros ainda não ganhou a devida atenção dos medievalistas em geral. Ora, a questão é capital, uma vez que, pilares da organização eclesiástica, os mosteiros estiveram no centro de diversas formas de organização social ao longo da Idade Média.

Como veremos mais adiante, quando tratada de frente por pesquisadores, a questão das fundações monásticas do deserto levou a algumas aporias (a propósito da veracidade ou não do isolamento original do eremitério/

\footnotetext{
1 Para um esforço taxonômico da solidão religiosa ver: McGRAW John. God and the problem of loneliness. Religious Studies, n. 28, 3. Londres: Cambridge University Press, 1992, p. 319-346.
} 
mosteiro) para as quais o presente artigo propõe algumas soluções a partir de um estudo hermenêutico. De fato, para compreender melhor o lugar da solidão na organização social medieval, irei investigar a construção discursiva do lugar da solidão na paisagem medieval. ${ }^{2}$ Pretendo demonstrar que, dialeticamente, o estatuto deste espaço se funda em relações humanas estabelecidas a partir de um desejo geral de isolamento e que esta vontade de se separar de outras pessoas alimenta e é alimentada pelo agenciamento do que chamei de "vocabulário da solidão". Um vocabulário que se articula ao discurso de legitimação da solidão existente no seio da sociedade cristã medieval. Um vocabulário, enfim, marcado por uma topografia situada entre o campo das representações e o das práticas, entre o deserto-floresta dos santos eremitas e o baldio dos fundadores dos novos mosteiros.

O artigo está dividido em duas partes. Na primeira será apresentada uma crítica ao atual discurso historiográfico sobre a solidão medieval. Pretende-se, assim, chamar a atenção do leitor para a necessidade de se identificar claramente os limites de um senso comum hegemônico entre os historiadores do deserto medieval: sua identificação com a floresta e com o isolamento absoluto do religioso que se encontraria completamente sozinho diante de Deus. Trata-se de uma desconstrução historiográfica capital para a segunda etapa de nosso percurso, a saber, o estudo dos fundamentos e das etapas operativas da transferência do deserto bíblico (modelo absoluto de solidão) para as realidades europeias medievais.

\section{Historiografia: o tópos florestal e a ocupação fundiária do deserto}

\section{a. O tópos florestal}

A identificação entre o deserto-floresta e a solidão parece ser algo evidente por si só para uma boa parte dos medievalistas e isto, sobretudo, a partir do artigo de Jacques Le Goff sobre "o deserto-floresta no Ocidente

\footnotetext{
${ }^{2}$ Guizard-Duchamp lembra que a noção atual de "paisagem" remonta ao século XVI, quando era estreitamente ligada a ideia de representação pictórica. GUIZARD-DUCHAMP, Fabrice. Les espaces du sauvage dans le monde franc: réalités et représentations. In: XXXVII ${ }^{\mathrm{E}}$ CONGRES DE LA SHMES, 2006. Construction de l'espace au Moyen Âge: pratiques et représentations. Paris: Publications de la Sorbonne, 2007, p. 117-129 (p. 127). Ver também FRANCESCHI, Catherine. Du mot paysage et de ses équivalents dans cinq langues européennes. In: COLLOT, Michel (org.). Les enjeux du paysage. Bruxelas: Ousia, 1997, p. 75-111.
} 
medieval" publicado em 1985. Assim disse um dos maiores historiadores da segunda metade do século XX: "nesse mundo [de clima] temperado sem grandes extensões áridas, o deserto, isto é, a solidão será de uma natureza totalmente diferente, quase o contrário do deserto, do ponto de vista da geografia física. Ele será a floresta" ${ }^{3}$

Editado em obras que se ocupavam do estudo do imaginário e do maravilhoso medieval, o texto de Le Goff privilegia o aspecto selvagem da solidão. Empregando a oposição entre natureza e cultura (categoria estruturante do pensamento científico ocidental, como bem demonstrou recentemente Philippe Descola), ${ }^{4}$ J. Le Goff distingue (mesmo que com certo grau de articulação) a cultura, de um lado, e o selvagem, de outro, esvaziando o ermo de toda possibilidade de atividade intelectual: "o deserto é o lugar mais distante da cultura erudita (savante)". ${ }^{5}$ No entanto, a concepção do deserto proposta pelo eminente medievalista não leva em conta um dado importante: por muitos séculos, os monges, verdadeiros especialistas da alta cultura, buscaram o isolamento físico e se tornaram também os grandes especialistas da solidão cristã medieval. ${ }^{6}$

A revisão do propósito de Le Goff a respeito da noção de "deserto-floresta" nos leva a fazer duas constatações importantes: a primeira é a ausência de uma explicação que demonstre como historicamente se chegou à analogia entre a floresta temperada e o deserto árido; a segunda diz respeito ao cuidado com o emprego de tais conceitos, uma vez que por detrás deles se esconde uma oposição difícil de ser aplicada diretamente ao mundo medieval (a oposição natureza/cultura). Construção histórica de uma analogia e efeito retórico-social de uma forma de pensar, eis dois novos pontos a serem tratados por quem estuda a solidão medieval. Em outras palavras, para compreender melhor tal objeto de estudo profundamente associado ao imaginário, digamos, poético, senão ideológico, o historiador deve diferenciar, de um lado, os efeitos retóricos de uma mentalidade urbana medieval (que foi,

3 LE GOFF, Jacques. Le désert-forêt dans l'Occident médiéval. In: Idem. Limaginaire médiéval. Paris: Gallimard, 1991 [1985], p. 59-75 (p. 61), grifos meus.

${ }^{4}$ DESCOLA, Philippe. Par-delà nature et culture. Paris: Gallimard, 2005.

5 LE GOFF, Jacques, op. cit., 1991, p. 72.

6 No sentido indicado aqui, a ideia de Le Goff parece ter sido matizada por GREGOIRE, Réginald. La foresta come esperienza religiosa. In: L'ambiente vegetale nell'alto Medioevo. Spoleto: Centro Italiano di Studi sull'Alto Medievo, 1990, p. 663-707 (p. 695): “La foresta non è dunque un luogo di erudizione umana, ma un ambiente che predispone alla contemplazione e all'esperienza mistica. La riflessione sulla realtà naturale (vegetazione, ecc.) offre un insegnamento, che è l'oratio, non la lectio". 
aliás, alimentada por ideais românticos a partir do século XVIII) e, de outro, a dinâmica sociocultural que construiu tal forma de discurso.

Guardemos em mente esses dois elementos norteadores da análise documental a ser empreendida na segunda parte deste artigo. Antes devemos nos ater mais alguns instantes aos impactos e aos desenvolvimentos dos estudos sobre o deserto difundidos a partir do texto seminal de Jacques Le Goff. De fato, para que possamos compreender melhor a polissemia social do deserto medieval, será útil aprofundar ainda mais nossa análise da definição, digamos, "literária" (no sentido de um conteúdo profundamente ligado ao imaginário e ao maravilhoso difundidos por textos narrativos) da solidão. Entre os medievalistas, esta forma de definição se tornou autoevidente nos últimos anos. Pode-se dizer que ela se constituiu em um tópos, um senso comum, de grande força e cuja eficácia retórica levou historiadores a prescindir de uma de suas ferramentas mais importantes: o aparato crítico e de erudição.

Abordarei aqui três casos dessa ausência de referências ou de notas de rodapé que revelam, a meu ver, menos um equívoco pontual de cada um dos colegas em questão do que um sintoma da forma pouco crítica com que a solidão vem sendo, há décadas, estudada pelos historiadores.

Em uma importante coletânea a respeito do eremitismo medieval publicada na revista francesa Médiévales em 1995, Catherine Santschi dava a primeira forma acabada ao tópos da solidão na retórica dos medievalistas:

(...) solitude est d'abord un désert, non pas un lieu où il n'y a personne, mais un lieu situé hors du monde, de la vie et de la hiérarchie sociale, un lieu où les "valeurs" du monde pouvoir, argent, liens sociaux de toutes sortes - n'ont plus cours et font place à Dieu seul. ${ }^{7}$

Seja pelo fato de o texto não apresentar nesta passagem nenhuma nota que pudesse atribuir origem a tal definição da solidão, seja por não ter podido encontrar nenhuma formulação idêntica em outros textos historiográficos anteriores, atribuo a Santschi a origem das passagens que virão a seguir. Em todo caso, como o texto de Le Goff evocado acima nos permite compreender, a definição dada por Santschi à solidão cristã medieval nada mais é do que um desdobramento lapidar de uma forma de pensamento paradigmaticamente calcada na existência de uma oposição radical e insuperável entre o domínio do humano (cultura) e do divino (natureza). Cabe aqui

SANTSCHI, Catherine. La solitude des ermites. Enquête en milieu alpin. Médiévales, n. 28. SaintDenis: Centre de Recherche de l'Université de Paris VIII, 1995, p. 25-40 (p. 25). Grifo da autora. 
lembrar, como bem apontou Jérôme Baschet, que a Igreja medieval defendia a dualidade (articulação entre corpo e alma visando espiritualizar o corpóreo) por meio de seus representantes, imputando aos dissidentes (genericamente chamados de maniqueístas) a crença em um mundo fundado no dualismo (separação dicotômica das esferas). ${ }^{8}$ Deste modo, percebemos que o tópos historiográfico se distancia da realidade medieval ao compreender a solidão no período em seu aspecto mais genérico, qual seja, o de oposição ao mundo material.

Passados quase quinze anos, a definição reaparece entre os medievalistas. A semelhança com a sequência de palavras empregadas por Santschi é um tanto desconcertante, uma vez que, em nenhum dos casos, os autores fazem referência à fonte que inspirou suas definições da solidão na Idade Média. No primeiro caso se trata de um livro publicado a partir de uma tese de doutorado defendida em 2004. Transcrevo abaixo a passagem, colocando em itálico as palavras que já apareciam na definição de Santschi:

(...) une solitude est d'abord un désert, autrement dit un lieu situé hors du monde, de la vie, de la hiérarchie sociale, un lieu où les "valeurs" du monde - pouvoir, argent, liens sociaux de toutes sortes n'ont plus cours et font place à Dieu seul. ${ }^{9}$

No mesmo ano, em um artigo sobre os monges que escolheram se isolar na ilha de Lérins, encontramos novamente uma sequência de palavras bastante próxima da empregada em 1995 (novamente em itálico apresento as palavras duplicadas):

(...) la solitude n'est donc pas, un lieu où il n'y a personne, c'est un désert, un lieu hors du monde et de la hiérarchie sociale, un lieu où les "valeurs" du monde - pouvoir, argent, liens sociaux de toutes sortes - ont laissé la place uniquement à Dieu. ${ }^{10}$

Como indiquei há pouco, é mais importante analisarmos os significados de tais definições do que nos atermos ao fato de que as semelhanças entre as definições são evidentes, mas sem que apareçam referências mútuas ou

${ }^{8}$ BASCHET, Jérôme. Âme et corps dans l'Occident médiéval: une dualité dynamique entre pluralité et dualisme. Archives de sciences sociales des religions, n. 112. Paris: CNRS, 2000, p. 5-30.

9 GUIZARD-DUCHAMP, Fabrice. Les terres du sauvage dans le monde franc: IVe-IXe siècle. Rennes: PUR, 2009, p. 192.

${ }^{10}$ GIOANNI, Stéphane. "Être véritablement moine": les représentations de l'identité ascétique dans la pastorale lérinienne ( $\mathrm{V}^{\mathrm{e}}-\mathrm{VI}^{\mathrm{e}}$ siècles). In: CODOU, Y. \& LAUWERS, M. (org.). Lérins, une île sainte de l'Antiquitéa au Moyen Âge. (Collection d'Études Médiévales de Nice, 9) Turnhout: Brepols, 2009, p. 141-166 (p. 158). 
a outros autores. Podemos notar que "solidão" e "deserto" são tidos como sinônimos pelos três autores. Se Le Goff enfatizava a geografia física (florestal) como espaço privilegiado da solidão medieval, as três definições acima destacam a geografia espiritual (a falta de relações com o mundo dos homens) da solidão. Os dois aspectos são faces de uma mesma moeda, a saber, a convicção de que a noção medieval de solidão está profundamente ligada a um espaço, um lugar específico. Tal conclusão, de fato, se impõe quando lemos a documentação medieval e percebemos que apenas tardiamente (lentamente a partir do século XIII, mais rapidamente desde o século XIV) o campo semântico do isolamento faz referência ao que hoje entendemos por solidão. ${ }^{11}$ No entanto, ela se restringe apenas ao campo cultural (o imaginário a respeito da floresta e do mundo selvagem e a espiritualidade do abandono do mundo e da contemplação divina). Toda implicação social não apenas é diminuída, como é claramente descartada, uma vez que se trataria de um local "fora do mundo, da vida e da hierarquia social, um lugar onde os 'valores' do mundo - poder, dinheiro, laços sociais de todos os tipos - não mais existem". ${ }^{12}$ Deste modo, páginas e páginas a respeito de uma topografia sociocultural da solidão medieval permanecem ainda a serem escritas. Tentarei a seguir apresentar alguns de seus aspectos principais.

\section{b. A ocupação fundiária do deserto}

A configuração material do que poderíamos chamar "deserto florestal" medieval, em especial seu ecossistema, seu estatuto jurídico e seus usos ao longo do tempo, também já foi objeto de estudo de historiadores e arqueólogos. Georges Despy, partindo do estudo sobre o priorado dos cônegos de Oignies, próximo a Namur, no século XII, demonstra que o deserto, como espaço isolado e despovoado, não existe de fato quando lemos as fontes diplomáticas. Para ele, os documentos da prática demonstram que as terras qualificadas como sendo desertas em outros gêneros de documentos (em especial nas hagiografias e outros textos narrativos de cunho histórico) são, na verdade, sujeitas a tributos. A presença de tais práticas testemunhadas

\footnotetext{
${ }^{11}$ Proponho a seguinte definição para a noção de solidão atualmente em voga: a convicção pessoal, ao mesmo tempo emotiva e racional, de que se vivencia de modo solitário e sem auxílio algum - seja ele divino ou humano - uma experiência única que nos excede e que nos coloca em face de um desafio insuperável.

12 SANTSCHI, Catherine, op. cit., 1995, p. 25.
} 
rev. hist. (São Paulo), n. 173, p. 115-139, jul.-dez., 2015 http://dx.doi.org/10.11606/issn.2316-9141.rh.2015.105633
Gabriel de C. G. Castanho

A polissemia (social) do deserto: uma história do tópos histórico e historiográfico da solidão monástica no contexto latino medieval

pela documentação comprovaria que essas terras estariam, na verdade, inseridas no sistema social vigente calcado nas relações de homem a homem. Em suma, muitas terras tidas como desertas por uma documentação de forte cunho espiritual seriam, de fato, domínios explorados diretamente por homens que pagavam tributos àqueles que detinham os direitos sobre este espaço. ${ }^{13}$ Estamos aqui muito longe de um lugar alheio às riquezas e hierarquias sociais deste mundo.

Despy não é o único a pensar assim. Suas ideias reverberam outras enunciadas por Chris Wickham alguns anos antes. ${ }^{14}$ Para estes autores, existiria uma separação dicotômica entre os aspectos econômicos e espirituais da solitudo, cabendo aos últimos a função ideológica de ocultação de relações sociais de dominação bastante claras, duras e eficazes. Contudo, acredito que, apesar de importante, esta crítica de cunho materialista não dá conta da complexidade do lugar de solidão. Parece-me limitada e deformadora da totalidade histórica a ideia de que não há senão duas possibilidades neste caso: ou as terras são desertas (esvaziadas de toda forma de ocupação e de relações humanas) ou elas são ocupadas pelos homens (pois exploradas agricolamente). De fato, uma análise detalhada do vocabulário da solidão empregado pela documentação diplomática demonstra a existência de graus ou de formas diferentes de ocupação do solo. ${ }^{15}$ Essa variedade de relações sociais com o espaço pode gerar discordâncias semânticas entre os textos ditos das práticas e os textos de vocação espiritual, sem que um ou outro esteja "errado". Assim, um local pouco ocupado e qualificado na documentação como "deserto" corresponde às necessidades espirituais de separação do mundo, ainda que esse mesmo lugar possa, e mesmo deva, estar submetido à jurisdição de uma pessoa ou de uma instituição. É essa situação de algumas importantes ordens monásticas fundadas na virada dos séculos XI-XII, como os cartuxos, os grandmontanos e mesmo os cistercienses.

\footnotetext{
${ }^{15}$ DESPY, Georges. A propos de "déserts" dans les campagnes au XII siècle. In: MORNET, Elisabeth (org.). Campagnes médiévales: l'homme et son espace. Études offertes à Robert Fossier. Paris: Publications de la Sorbonne, 1995, p. 549-562 (p. 558-559).

${ }^{14}$ WICKHAM, Chris. European forests in the early Middle Ages: Landscape and land clearance. In: L'ambiente vegetale nell'alto Medioevo, t. 2. Spoleto: Centro Italiano di Studi sull'Alto Medievo, 1990, p. 479-548 (p. 483-484): "Von der Nahmer himself remarked that the concept of solitudo and the whole topos of isolation in hagiographies is a spiritual, not a economic one: we cannot read off the history of settlement from such terminology".

${ }^{15} \mathrm{Na}$ ausência de outros trabalhos sobre o tema, permito-me enviar a CASTANHO, Gabriel de Carvalho Godoy. Isolement, communauté et société. Sémantique de la solitude en contexte monastique latin (v. 1080-v. 1150). Tese de doutorado, Histoire et Civilisations, CEIFR, EHESS-Paris, 2013.
} 
Proposições como as de Despy e de Wickham alimentam a ideia de que as fundações monásticas in solitudine não são nada além de um tópos hagiográfico. Como vimos, embora largamente aceita, esta separação entre, digamos, as representações e as práticas do isolamento merecem ser revistas. Esta distinção demasiadamente dicotômica e artificial remonta às discussões de cunho arqueológico travadas a partir de meados dos anos 1960. ${ }^{16}$ Podemos, assim, resumir o ponto principal da polêmica: deve-se ou não falar em fundação no deserto quando um documento escrito atribui uma origem de tipo eremítico a uma determinada casa monástica, mas os "arquivos do solo" revelam a presença de um edifício? Por muito tempo os medievalistas debateram a questão sem, de fato, chegarem a um consenso ou a uma síntese que desse conta da variedade dos casos encontrados. De minha parte acredito que uma saída para o impasse esteja, aqui também, no sentido ambíguo da solidão medieval. Uma construção em ruínas, testemunha, ao mesmo tempo, de uma ocupação do solo mais ou menos distante no tempo assim como de seu abandono. Ou seja, a ruína, nesse caso, indica, ao mesmo tempo, a ocupação e a desocupação humana de um determinado local. A questão capital diz respeito então à reutilização de antigas infraestruturas por monges em meio rural.

É exatamente nesse ponto que o estudo da polissemia da palavra "deserto" pode auxiliar os pesquisadores a saírem da aporia em que se encontram. O estudo atento das palavras ajuda a revelar o papel do verbo "desertar" no campo semântico de "deserto". Desde Isidoro de Sevilha (560-636), os glossários medievais portam uma nuança importante entre os principais termos do vocabulário da solidão. Segundo Isidoro, "Heremum est inuia solitudo, ubi nunquam habitatum est, desertum ubi aliquando habitantum et derelictum est". ${ }^{17} \mathrm{Um}$ local em ruínas é, portanto, um lugar deserto, enquanto o ermo é um espaço jamais povoado. Distinção importante para a história semântica da solidão medieval, mas para a qual não seria possível dar aqui a atenção merecida, como o fizemos em outro trabalho. Mais importante para o propósito do presente artigo é constatar a existência de fato de uma polissemia intrínseca ao vocabulário da solidão.

\footnotetext{
${ }^{16}$ PRINZ, Friedrich. Frühes Mönchtum im Frankenreich: Kultur und Gesellschaft in Gallien, den Rheinlanden und Bayern am Beispiel der monastischen Entwicklung (4. bis 8. Jahrhundert). Munique/Viena: R. Oldenbourg, 1965, p. 250, fala em "alte Topos einer Gründung aus wilder Wurzel".

${ }^{17}$ ISIDORO DE SEVILHA. De differentiis uerborum ou Differentiarum siue de proprietate sermonum libri duo. In: CODOÑER, Carmen (ed.). Isidoro de Sevilla, Diferencias, livro I, par. 454 (201). Paris: Les Belles Letttres, 1992, p. 288.
} 
Reconhecer o sentido verbal (e adjetivo) do termo "deserto" nos permite, assim, valorizar o fato de que esse espaço pode trazer em si as marcas de uma ocupação anterior, reforçando o caráter relacional da noção em questão. De maneira mais simples: um espaço se torna deserto após ter sido desertado (abandonado) pelas pessoas que ali habitavam; ou seja, a própria noção de deserto pressupõe, em contexto latino medieval, a ocupação prévia do espaço e as marcas arqueológicas que dela decorrem. Assim, longe das ruínas indicarem a contradição de uma fundação monástica supostamente realizada in solitudine, a escolha de um local deserto serve, ao mesmo tempo, para facilitar a instalação material dos monges (por meio das benfeitorias já existentes) e assegurar o estatuto despovoado das terras escolhidas pelos religiosos (mesmo se ela foi abandonada há pouco tempo). ${ }^{18}$

Em suma, pode-se dizer que argumentos como os de Le Goff, Santschi e Despy, entre outros, apagam a ambiguidade fundadora da noção espacial de solidão medieval: o lugar deserto não é definido pela ausência ou não de ocupação humana, mas, sim, pela maneira como os homens ocupam e, sobretudo, valorizam esse espaço. Observadas deste ponto de vista social, nota-se a existência de uma relação de complementaridade entre as terras sujeitas a tributos, aquelas identificadas como desertos e aquelas onde se encontram edifícios em ruínas. Por essa razão tenho defendido que solidão medieval é uma relação social e não o seu contrário.

Sempre visando à superação da já indicada dicotomia historiográfica presente na interpretação do isolamento monástico medieval, a segunda parte deste artigo irá demonstrar que a noção medieval de solitudo se apoia em dois pilares: as tradições retóricas bíblica e clássica.

\footnotetext{
${ }^{18}$ Sobre a dupla valência do deserto para os monges ver: VON DER NAHMER, Dieter. Die Klostergründung "in solitudine" ein unbrauchbarer hagiographischer Topos? In: Hessisches Jahrbuch für Landesgeschichte, n. 22. Marburg: Arbeitsgemeinschaft der Historischen Kommissionen in Darmstad, 1972, p. 90-111 (p. 93).
} 


\section{Por uma semântica histórica da solidão ${ }^{19}$}

\section{a. A Bíblia e a metaforização do deserto}

Vimos anteriormente que os medievalistas normalmente se referem à documentação hagiográfica ou às narrativas de fundação monástica para tratar da solidão medieval. Seus estudos trabalham com a metaforização do deserto bíblico (assim como o espaço dos Pais do Deserto) aplicada a uma geomorfologia diferente: a floresta ou o ermo. Contudo, o fazem sem realmente levar em conta a problemática da transferência histórica da noção geográfica do deserto (do norte da África e do Oriente Médio) em direção à abstração metafórica deste espaço e sua relação com a noção de solidão empregada nos textos latinos medievais.

Para compreender essa transferência histórica é preciso nos deter alguns momentos na figura de linguagem seguida acriticamente por alguns medievalistas a partir de suas fontes. O deserto que aparece na documentação produzida no mundo latino medieval é, de fato, uma metáfora e não uma metonímia. Explicitar e analisar a diferença entre essas duas formas de expressão é capital se queremos compreender o sentido da solidão no período estudado. Primeiro, pois se trata da abstração de uma realidade empírica em direção a uma realidade simbólica criada pela imaginação cristã. ${ }^{20}$ Em

\footnotetext{
${ }^{19}$ O estudo aqui apresentado versa sobre a apropriação da tradição cristã oriental e clássica pelo mundo latino medieval. Neste sentido, são trabalhados autores fundamentais como Jerônimo, João Cassiano, João Crisóstomo e Quintiliano. Definir e analisar satisfatoriamente os usos daquilo que poderia vir a ser definido como o equivalente oriental do vocabulário latino da solidão (levando em conta todas as nuanças semânticas ligadas à língua grega tardo-antiga) exigiria a preparação de outro artigo. Assim, não irei abordar a elaboração patrística oriental sobre o tema. De fato, meu objetivo é analisar a metaforização enquanto processo de formação e de sedimentação semântica do vocabulário da solidão exclusivamente no âmbito da língua latina. Por fim, devo explicitar também que não pretendo realizar um estudo de hermenêutica bíblica. O objetivo deste artigo é outro, a saber, empreender uma análise acerca da realização histórica de um discurso por meio do estudo dos principais vocábulos que o compõem. Um discurso situado em um contexto cultural e social preciso materializado pela língua latina, em especial aquela empregada na Vulgata, simultaneamente grande instrumento da translatio do cristianismo antigo para o contexto medieval latino e o único "glossário" universalmente difundido por toda a Europa ao longo da Idade Média.

${ }^{20}$ FONTANIER, P. Les figures du discours [GENETTE, Gérard. Introdução.]. Paris: Flammarion, 1977 [1821], p. 99, classifica as metáforas como sendo relações de "ressemblance" que "consistent à présenter une idée sous le signe d'une autre idée plus frappante ou plus connue, qui, d'ailleurs, ne tient à la première par aucun autre lien que celui d'une certaine conformité ou analogie".
} 
seguida, pois não há uma relação necessária e objetiva entre a morfologia geográfica do deserto bíblico e aquela das florestas ou baldios europeus. ${ }^{21}$ É exatamente a ausência de relações necessárias entre as duas realidades empíricas que permite a construção sociocultural do deserto a partir da Alta Idade Média. Assim, precisar a figura de linguagem empregada na documentação analisada traz informações importantes para a pesquisa histórica das sociedades passadas. No caso do deserto cristão, a noção de metáfora evidencia o descompasso geomorfológico dos desertos em questão e, sobretudo, o processo de morfogênese deste lugar de solidão.

Vejamos alguns dados importantes a respeito da transferência do vocabulário da solidão do Oriente para o Ocidente. Na Vulgata, a solidão aparece contextualmente próxima ao deserto. Das 158 ocorrências da palavra solitudo (solitudine 69 vezes, solitudinem 48, solitudinis 20, solitudines 11, solitudo 7, solitudinibus, solitudini e solitudinum 1 só vez cada), mais de 90 são precedidas pela preposição "in", confirmando sua relação com o espaço. Urbs (3), Iordanes (3), Sinai (4), campester (5), ciuitas (7), mare (11), uia (11), Aegyptus (11), desertum (15), terra (24), fazem parte do vocabulário empregado em torno da solidão. ${ }^{22}$ No outro extremo, palavras como eremus, secretum, silentium, quies e contemplatio estão ausentes desse vocabulário.

Uma análise mais fina faz aparecer palavras diretamente associadas à solitudo (usadas imediatamente antes ou depois dela) e cuja relação semântica é mais forte. Normalmente, se trata de uma qualificação ou de um nome próprio, como é o caso do Mar Morto, chamado três vezes de "mare Solitudinis". Nesse grupo a palavra "uasta" marcou profundamente a imagem do deserto cristão.

\section{b. A "uasta solitudo" bíblica}

A fórmula bíblica "uasta solitudo" está estreitamente ligada ao deserto apresentado no Pentateuco. Trata-se de reforçar, com essa expressão, o sentido comunitário de provação espiritual atribuído ao ecossistema inóspito. Em suas versões latinas, "vastidão" e "solidão" exercem uma função discursiva

\footnotetext{
${ }^{21}$ FONTANIER, P., op. cit., 1977, p. 79, qualifica a metonímia como uma relação de "correspondance" fundada "dans la désignation d'un objet par le nom d'un autre objet qui fait comme lui un tout absolument à part, mais qui lui doit ou à qui il doit lui-même plus ou moins, ou pour son existence, ou pour sa manière d'être".

22 Os números vêm da edição de FISCHER, Bonifatio; GRIBOMONT, Johanne; WEBER, Robertus et alii (ed.). Biblia sacra juxta vulgatam versionem. Stuttgard: Württembergische Bibelanstalt, 1969. Se as palavras podem variar de acordo com a edição, as proporções relativas permanecem mais ou menos constantes.
} 
bastante conhecida pelos oradores antigos: a amplificação retórica do objeto narrado. ${ }^{23}$ Tal prática visa o convencimento (mais do que a demonstração descritiva) ao acionar a carga emotiva associada a cada uma das palavras e criar uma dupla modalidade de adversidade. Como veremos a seguir, o uso dos termos tem como resultado a consolidação da coesão interna da comunidade de fiéis (face aos "inimigos" - tanto naturais, como sobrenaturais - que ameaçam o grupo escolhido pelo criador) e de sua relação com Deus. Assim, no texto divino, o lugar de solidão atravessado por Israel solda uma à outra as esferas social e celeste. Vejamos detalhadamente as duas ocorrências de "uasta solitudo" na Bíblia.

O primeiro emprego de "uasta solitudo" aparece em Números, livro que narra a travessia do deserto, bem como as provações e murmurações do povo escolhido durante esse período. É exatamente nesse contexto que a expressão estudada foi utilizada na tradução latina do texto sagrado. Em Canaã, e temendo os combates contra os povos locais pela terra prometida, Israel abandona sua fé nos desígnios divinos ao dizer que preferiria morrer na vasta solidão ao invés de ser assassinado ou ter seus filhos e esposas aprisionados sob a espada dos inimigos: "utinam mortui essemus in Aegypto: et in hac vasta solitudine utinam pereamus et non inducat nos Dominus in terram istam, ne cadamus gladio, et uxores ac liberi nostri ducantur captivi" (Números 14, 3). Aqui, a vasta solidão faz referência às regiões desérticas (Farã no Cades) situadas no entorno de Canaã. Israel coloca em dúvida o apoio divino, que havia sido renovado pela Aliança, no momento da confrontação com outros povos. Além de ser um lugar árido e rochoso, a "uasta solitudo" (muitas vezes traduzida pelo termo "deserto" nas versões modernas da Bíblia) remete diretamente às provações divinas impostas ao povo escolhido e à crença, por parte de Israel, de que fora, diante de povos inimigos, abandonado por Deus.

A segunda ocorrência da expressão se encontra no Deuteronômio, livro de cunho normativo que visa confirmar as leis divinas dadas ao povo eleito. Em seu cântico sobre a história de Israel, Moisés opõe a vida feliz de seu povo sob a proteção de Deus à vida de provações "in terra deserta in loco horroris et vastae solitudinis" 24 (Deuteronômio 32, 10). Contrariamente ao que uma

\footnotetext{
${ }^{25}$ Sobre a amplificatio ver, por exemplo, o capítulo 4 do livro VIII da Institutio Oratoria de Quintiliano (30-96) que trata dos quatro tipos de amplificação: incrementum, comparatio, ratiocinatio e congeries (esse último estando perfeitamente de acordo com a acumulação semântica expressa em "uasta solitudo").

${ }^{24}$ A frase será amplamente utilizada em narrativas hagiográficas medievais.
} 
parcela dos historiadores tem afirmado a respeito do período medieval (o deserto como local privilegiado de contemplação divina, abordado acima), o texto bíblico, em sua versão latina, apresenta esta terra deserta como sendo um local terrível e de vasta solidão, justamente por ser um espaço onde a intervenção divina não se manifesta de maneira positiva, se tornando, assim, um local (de certo modo) abandonado por Deus.

Nas duas ocorrências da expressão "uasta solitudo" existentes na Vulgata, as palavras empregadas articulam os sentidos material (aridez que torna impossível a ocupação perene do local) e espiritual (ausência de manifestações protetoras por parte de Deus) do deserto para criar uma imagem que irá se difundir amplamente na cristandade latina medieval: um lugar inóspito e isolado que suscita o terror entre os seguidores de Deus, tal como aconteceu com Israel quando de sua estada em terras estrangeiras (opostas à terra prometida). Um terror fundado sobre a crença de que Deus abandonou seus seguidores para que esses possam provar sua fé mesmo em condições duramente adversas. Em suma, o sofrimento de Israel, que, apartado de sua terra prometida, se encontra em um deserto tido como terra estrangeira, e a deserção divina são as principais marcas da vasta solidão bíblica.

\section{c. As tópicas do "locus horridus" e do "locus amoenus"}

Como explicar a passagem dessa imagem amplamente negativa da solidão bíblica marcada pela ausência (perda da terra prometida e do auxílio divino) em local privilegiado da presença de Deus (e sua contemplação) tão comum nos textos medievais? A resposta concerne a diferentes aspectos do vocabulário da solidão, como veremos nas páginas abaixo. O primeiro deles diz respeito ao referencial discursivo sem dúvida já presente na mente do principal responsável pela tradução latina do texto bíblico, Jerônimo (c. 347420), mas também de seus antecessores e sucessores no trabalho de adaptação do verbo divino à língua latina. De fato, a presença da tradição retórica clássica é tão forte em Jerônimo que este teme ser mais ciceroniano do que cristão, como confessa penitencialmente em sua carta a Eustochium (384). ${ }^{25}$ Dessa maneira, acredito ser impossível compreender a passagem da negativa

\footnotetext{
25 "Interrogatus condicionem christianum me esse respondi. Et ille, qui residebat: 'mentiris', ait, 'ciceronianus es, non christianus; ubi thesaurus tuus, ibi et cor tuum'". Hieronumus. Epistola 22, In: HILBERG, Isidorus. (ed.). Epistolae, I. (Corpus Scriptorium Ecclesiasticorum Latinorum - CSEL, 54) Viena: Verl. der Österreichischen Akademie der Wissenschaften, 1996 [1910], p. 190.
} 
rev. hist. (São Paulo), n. 173, p. 115-139, jul.-dez., 2015 http://dx.doi.org/10.11606/issn.2316-9141.rh.2015.105633
Gabriel de C. G. Castanho

A polissemia (social) do deserto: uma história do tópos histórico e historiográfico da solidão monástica no contexto latino medieval

vasta solidão bíblica para a edificante solidão medieval se não levarmos em conta o peso que a retórica latina e sua tópica exerceram nesse processo de tradução da cultura antiga para o mundo latino medieval.

É impossível para quem estava embebido na erudição latina clássica retirar e deixar de lado suas lentes retóricas ao realizar a tradução da solidão antiga para o mundo cristão ocidental. No imaginário dos primeiros cristãos, a "uasta solitudo" bíblica faz, assim, parte da tópica antiga do "locus horridus" e do "locus amoenus". ${ }^{26} \mathrm{Se}$, na Antiguidade clássica, era o lugar ameno que estimulava a prática da filosofia, seu oposto, o lugar terrível, vai, na Idade Média, favorecer a ascensão a Deus. ${ }^{27}$ Embora o processo de transformação dos loca seja razoavelmente bem conhecido por estudiosos da literatura latina antiga e tardo-antiga, nos faltam pesquisas que proponham uma cronologia para a mudança semântica responsável pela transformação da solidão de lugar terrível em lugar ameno. Lembro apenas que tal percurso pode aparecer em uma mesma narrativa, como é o caso da fundação monástica de Saint-Évroult. Após a tentativa frustrada de se estabelecer em um lugar agradável (amoenus), abundante em madeira e água, ${ }^{28}$ Évroult parte para uma floresta inóspita descrita como "uastissima loca solitudinis" e dominada por bandidos, animais ferozes e uma densidade terrível de árvores. ${ }^{29}$ Foi nesse local sombrio que o

${ }^{26}$ As bases descritivas da retórica do locus amoenus foram colocadas por CURTIUS, Ernst Robert. A literatura europeia e a Idade Média latina. Tradução. São Paulo, Hucitec/Edusp, 1996 [1948], p. 254-258 (no capítulo 10, “A paisagem ideal”, p. 241-262). Ver também THOSS, Dagmar. Studien zum locus amoenus im Mittelalter. Viena: Braumüller, 1972.

27 EDWARDS, Mark. Locus horridus and locus amoenus. In: HARDIE, Philip $\mathcal{E}$ WHITBY, Mary (ed.). Homo viator. Classical essays for J. Bramble. Bristol/Oak Park: Bristol Classical Press/Borchazy-Carducci, 1987, p. 267-276.

${ }^{28}$ CHIBNALL, Marjorie. The ecclesiatical history of orderic vitalis, vol. 3, livro VI, 9, iii.54. Oxford: Carendon Press, 1972, p. 268: "Qui per Oximensem pagum in locum qui Monsfortis dicitur uenerunt, ibique, quia locus amenus siluis et fontibus abundabat hospitati sunt; et aliquandiu solitariam uitam ducentes sancte uixerunt".

${ }^{29}$ Ibidem, VI, 9, iii.56, p. 270: "Quae silva densitate arborum horribilis, crebris latronum frequentata discursibus, habitationem praestabat immanibus feris. Cumque intrepidis gressibus uastissima loca solitudinis peragrarent..." Ainda sobre a imagem negativa do local de solidão finalmente escolhido por Évroult ver a descrição dada por um dos bandidos que ali habitam (Ibidem. VI, 9, iii.57, p. 272): "Et admirans eorum constantiam, et in Christi seruitio perseuerantiam; ait: 'O monachi, quae causa turbationis uos has partes coegit adire? Uel quomodo praesumpsistis in tanta hospitari solitudine? Non optimum locum inuenistis. An nescitis quia hic est locus latronum, et non heremitarum? Huius nemoris incolae rapina uiuunt proprioque uiuentes labore consortes pati nolunt. Non diu tuti hic esse potestis. Praeterea arua inculta et infructuosa, uestroque labori inuenistis ingrata'". 
rev. hist. (São Paulo), n. 173, p. 115-139, jul.-dez., 2015 http://dx.doi.org/10.11606/issn.2316-9141.rh.2015.105633
Gabriel de C. G. Castanho

A polissemia (social) do deserto: uma história do tópos histórico e historiográfico da solidão monástica no contexto latino medieval

religioso, após a intervenção de um anjo, encontrou a tranquilidade necessária para realizar sua vocação. ${ }^{30}$

Habitar o "locus horridus", sob a forma do deserto marcado pela grande desolação da paisagem e pela lógica bíblica da provação (da fé do povo escolhido) conduz os religiosos a se voltarem para Deus. De certo modo, é seguindo esse modelo bíblico de ascensão espiritual que os Pais do Deserto encontraram os oásis que lhes permitiram ultrapassar as limitações do meio ambiente inóspito. Entre o lugar terrível e o lugar ameno é a tópica do espaço protegido - sob a forma do porto, da sombra das palmeiras etc. - situado no tumulto do século ou entre as violências da natureza que acabará por aparecer reiteradas vezes na documentação medieval. ${ }^{31}$ É a articulação entre esses dois elementos aparentemente antagônicos que opera a transformação da dureza do deserto em fruição espiritual. ${ }^{32}$ Não devemos esquecer, final-

${ }^{30}$ DELAPLACE, Christine. Aux origines du "désert" en Occident. Érémitisme et premières fondations monastiques en Gaule et en Italie aux Ve-VIe siècles après Jésus-Christ. In: BRUNET, Serge; JULIA, Dominique; LEMAITRE, Nicole (org.). Montagnes sacrées d'Europe. Actes du colloque "Religion et montagnes". Tarbes, 30 mai-2 juin 2002. Paris: Publications de la Sorbonne, 2005, p. 217-226 (p. 224). Delaplace lembra com razão que o percurso dos eremitas hagiográficos é muitas vezes o mesmo: primeiro eles devem atravessar um deserto terrível para depois alcançar uma solidão agradável.

31 João Crisóstomo (c. 349-407), bispo de Constantinopla, é tido com a principal origem da metáfora do porto que será desenvolvida por autores cristãos ao longo dos séculos medievais. Em sua homilia sobre a penitência encontramos a imagem da quietude do ermo sob a forma do porto que se encontra protegido das tempestades e onde os exercícios espirituais podem acontecer longe dos barulhos do mundo. JOÃO CRISÓSTOMO. Homiliae IX de Poenitentia, 5. In: MIGNE, Jacques-Paul (ed.). Patrologiae cursus completus: series graeca, n. 49, col. 307. Turnhout: Brepols, 1862: "Hi namque tumultum saeculi fugientes, atque ad ipsa montium cacumina currentes, tuguria in eremi quiete veluti in tranquillo quodam portu figentes, jejunium ceu commercii vitaque socium susceperunt. Quare angelos ex hominibus illos fecit: non illos modo, sed et in urbibus quotquot se tolerantes invenit, ad ipsum philosophiae culmen evehit". A articulação entre o espaço da solidão e a tranquilidade do porto também aparece em sua homilia sobre Mateus 14, 23-24. Crisóstomo fala da solidão como "mater tranquilitatis" que permite aos fiéis se libertarem das tribulações do século, tal como um porto de quietude. JOÃO CRISÓSTOMO. Homiliae L. In: Ibidem, n. 58, col. 503-504: “Cur in montem ascendit ? ut nos doceat, commodum esse desertum, commodam solitudinem, eum deo supplicandum est. Ideo saepe deserta petit, ibique pernoctat orans, ut nos moneat, et tempus et locum ad tranquille precandum opportunum esse quaerendum. Solitudo enim tranquillitatis mater est, quiestique portus, ab omni nos tumultu liberans. Ille quidem his de causis illuc ascendit". Sobre João Crisóstomo ver BRÄNDLE, Rudolf. Jean Chrysostome (349-407). "Saint Jean Bouche d'Or". Christianisme et politique au IVe siècle. Paris: Cerf, 2003 [ed. orig. Stuttgart, 1999]. 32 É preciso destacar que a metáfora do porto como elemento de fusão do "locus horridus" e do "locus amoenus" é também tributária das narrativas bíblicas e patrísticas que associam profetas e eremitas enquanto destinatários de benesses divinas. Assim, a tópica da proteção divina concedida àqueles que se isolam será reaproveitada pelos latinos ao traduzirem a experiência de tentações vivenciadas no deserto por profetas como Elias (3 Reg. 17: 2-6 e 19: 9-15) ou pelos primeiros eremitas como santo Antão. Entre uma personagem e outra temos, além do próprio Cristo, João Batista, a "vox clamantis in deserto" segundo Mc.1:3 (paradoxalmente isolado no deserto 
mente, que o próprio texto divino dá ensejo ao desenvolvimento da articulação entre os dois extremos por meio da descrição da estada e dos combates do Cristo no deserto (Mc. 1, 12-13 ; Mt. 4, 1-11 ; Lc. 4, 1-13).33

\section{d) A retórica das fundações monásticas}

A complexidade do campo semântico da solidão associado ao deserto demonstra a importância das nuanças estabelecidas a partir do longo processo de metaforização espiritual do emprego geográfico e ecológico da "uasta solitudo". Como vimos, esse binômio inicialmente era associado a um espaço árido e rochoso específico e se tornará um tópos útil na descrição espiritual de diferentes ecossistemas durante a Idade Média. O ecossistema original não existindo na Europa, resta somente sua representação, cujos aspectos principais são a grande extensão vazia ou fracamente habitada e onde os animais, as plantas e o relevo transformam esse espaço em um lugar ameaçador ("locus horridus"). Os contornos desta topografia da solidão são perfeitos para as narrativas de fundações monásticas de origem eremítica que transformam o lugar terrível em lugar de beatitude, a forma cristianizada da tópica do lugar ameno.

Já percorremos, no presente artigo, alguns dos mais importantes aspectos dessa complexa questão (em torno da fundação de novos mosteiros em locais de solidão). No entanto, é preciso destacar um aspecto fundamental: o efeito ideal e material do emprego da retórica da solidão nos relatos de fundação monástica no deserto. Meu propósito será aqui necessariamente breve, uma vez que uma análise mais detalhada nos levaria a redigir outro artigo exclusivamente a respeito da presença dessa temática nos textos ha-

\footnotetext{
e inserido nas redes de conversão), que será amplamente usado pelos latinos como modelo da fusão entre as figuras proféticas e eremíticas, fusão essa que marcará profundamente a tópica do ermo na Europa medieval.

${ }^{33}$ Embora façam referência à estada do Cristo no desertum (o termo solitudo não foi aqui empregado por Jerônimo), essas passagens interessam pouco ao propósito do presente artigo uma vez que: 1) das 158 ocorrências de solitudo na Vulgata, apenas cinco aparecem no Novo Testamento; 2) como evocado anteriormente, o polo semântico principal do vocabulário da solidão medieval (real objeto desta pesquisa e não meramente o deserto árido e simbólico dos primeiros cristãos) se encontra na expressão "uasta solitudo" que aparece somente no Velho Testamento. Nesse sentido, vale destacar que Mc. 1, 12-13 ; Mt. 4, 1-11; Lc. 4, 1-13 estão calcados na tópica da vasta solidão analisada acima. De fato, o isolamento do Cristo no deserto retoma, enquanto lugar comum retórico, a semântica do lugar de provação espiritual apresentado no velho testamento, a saber, a imposição de um suposto distanciamento entre Deus e seu povo que ficaria assim à mercê das tentações demoníacas.
} 
giográficos. ${ }^{34}$ Karin Schlapbach, ao tratar da mudança do lugar horrível em lugar de graça engendrada pelo monasticismo da Antiguidade tardia, afirma que é através do combate de eremitas e monges contra a hostilidade terrível da solidão que os religiosos ultrapassam a matéria, dando lugar a uma relação agradável e harmoniosa com a natureza. ${ }^{35}$ Contudo, esse aspecto ideal da solidão diz respeito apenas a uma parte da realidade medieval. De fato, como bem disse Nicolas Schroeder a propósito da fundação florestal de Stavelot-Malmedy, a expressão "uasta solitudo" visa eclipsar a "proteção e, portanto, [a] dominação social" que transformou esse espaço em local deserto, ou seja, abandonado. Consequentemente, "apresentar a floresta como uma imensa 'reserva de caça' ou um lugar mau e perigoso no qual o homem de armas e o homem da Igreja colocam a prova sua arte da caça, sua bravura e sua fé significa sonhar um ideal e reduzir ao silêncio a dominação que ele implica" ${ }^{36}$ Assim, a sublimação do espaço material e sua consequente espiritualização pode muitas vezes indicar um processo social de apropriação (domesticação) do espaço. Acredito que o emprego do vocabulário da solidão é, nesse sentido, um meio de dominação que visa garantir aos profissionais do ermo (monges e eremitas) o controle exclusivo sobre suas terras.

\section{e. Eremus e latinização do espaço da solidão}

A presença do termo eremus no campo semântico da solidão espacial bíblica é surpreendentemente fraca. Na Vulgata, encontram-se 365 frases com

\footnotetext{
${ }^{34}$ Embora de realização lenta, dadas as dificuldades inerentes aos relatos hagiográficos (variabilidade terminológica entre os manuscritos de uma mesma vita, datações e autorias incertas) e a imensa quantidade de documentação, pretendo desenvolver, nos próximos anos, um estudo sistemático da retórica da solidão empregada nas vidas de santos medievais.

${ }^{35}$ SCHLAPBACH, K. The pleasance, solitude and literary production. The transformation of the locus amoenus in late Antiquity. Jahrbuch für Antike und Christentum, n. 50. Münster: Aschendorf, 2007, p. 34-50 (p. 43). GUIZARD-DUCHAMP, Fabrice, op. cit., 2009, p. 240, lembrou corretamente que apesar da forte influência da retórica antiga "la vision poétique de la nature a pris un chemin original en Occident. Les clichés, les lieux communs emplissent les évocations paysagères laissant peu de place pour l'élan spontanée. La nature sauvage est d'abord l'auvre de Dieu et c'est un sentiment de Création qui est exalté, plutôt qu'un sentiment de nature".

${ }^{36}$ SCHROEDER, Nicolas. In locis vaste solitudinis. Représenter l'environnement au haut Moyen Âge: l'exemple de la Haute Ardenne (Belgique) au VII siècle. Le Moyen Âge, n. 116. Bruxelas: De Boeck, 2010, p. 9-35 (33-34) (DOI: 10.3917/rma.161.0009). Sobre a importância de uma história social da paisagem ver, por exemplo, p. 34: "nier l'activité économique, les modes de production, la paysannerie ainsi que la compénétration entre nature et culture équivaut à exprimer et à légitimer les rapports sociaux dans une description du paysage".
} 
rev. hist. (São Paulo), n. 173, p. 115-139, jul.-dez., 2015 http://dx.doi.org/10.11606/issn.2316-9141.rh.2015.105633
Gabriel de C. G. Castanho

A polissemia (social) do deserto: uma história do tópos histórico e historiográfico da solidão monástica no contexto latino medieval

desertus, 157 com solitudo (uma frase com duas ocorrências) e somente 8 com eremus. A proporção será bastante diferente quando mudamos de escala e analisamos um corpus documental mais amplo composto pelas centenas de volumes de importantes coleções como o Corpus Christianorum (Continuatio Mediaevalis e Series latina) e a Monumenta Germaniae Historica. ${ }^{37}$ A tabela abaixo apresenta, segundo os grandes períodos propostos pela Cross Database Searchtool, as quantidades totais de frases em que aparece um dos seguintes termos: eremus, solitudo e desertus.

\section{Tabela 1}

Frases com eremus, solitudo e desertus por grandes períodos ${ }^{38}$

\begin{tabular}{|c|c|c|c|c|c|c|c|c|}
\hline Palavras & \multicolumn{2}{|c|}{$\begin{array}{c}\text { Antes do final } \\
\text { do século II }\end{array}$} & \multicolumn{2}{|c|}{$\begin{array}{c}\text { Início do } \\
\text { século III } \\
\text { até 735 }\end{array}$} & \multicolumn{2}{|c|}{736 a 1500 } & \multicolumn{2}{|c|}{1501 a 1965} \\
\hline Eremus & 0 & $0 \%$ & 1.129 & $17,17 \%$ & 1.651 & $16,32 \%$ & 48 & $4,02 \%$ \\
\hline Solitudo & 361 & $37,44 \%$ & 1.483 & $22,55 \%$ & 2.727 & $26,95 \%$ & 163 & $13,65 \%$ \\
\hline Desertus & 603 & $62,56 \%$ & 3.962 & $60,28 \%$ & 5.737 & $56,73 \%$ & 983 & $82,33 \%$ \\
\hline Total & 964 & $100,00 \%$ & 6.574 & $100,00 \%$ & 10.115 & $100,00 \%$ & 1.194 & $100,00 \%$ \\
\hline
\end{tabular}

Assim, na Idade Média, eremus será amplamente empregado. De fato, o uso do termo eremus durante o período será um fato capital na história semântica da solidão, marcando a importância dessa época na história social do isolamento ocidental. A despeito da queda geral no número de frases empregando o vocabulário espacial da solidão a partir do século XVI, percebemos o estabelecimento da hegemonia do termo desertus a partir de

\footnotetext{
37 Essa imensa massa de documentos (mais de 114 milhões de palavras) se torna abordável de maneira sistemática por meio da Cross Database Searchtool (Centro Traditio Litterarum Occidentalium - CTLO e Brepols) produzida pela editora Brepols. Sua base de dados é composta ainda pelo Archive of Celtic-Latin Literature e pelo Aristoteles Latinus, entre outras coletâneas documentais. Para uma listagem exaustiva de todos os documentos disponíveis por meio da CDS ver: http://www.brepolis.net/BRP_Info_En.html?show=info.

${ }^{38}$ Os números aqui apresentados dizem respeito aos dados disponibilizados pela Cross Database Searchtool até o ano de 2013. Uma vez que essa base de dados é constantemente enriquecida por novos textos, as quantidades apresentadas na tabela podem se alterar. Contudo, dificilmente as proporções relativas entre os termos serão drasticamente alteradas.
} 
então. Hegemonia que nos permite compreender melhor a razão pela qual alguns medievalistas contemporâneos privilegiaram a noção de deserto em suas definições da solidão medieval, como vimos acima. A tabela nos indica, finalmente, que a adaptação da tradição oriental do deserto ao mundo latino ocorreu justamente durante uma longa Antiguidade tardia por meio do aparecimento fulgurante do termo eremus nesse período (sem menosprezar a clara perenização do termo ao longo da Idade Média). No que concerne ao presente estudo da polissemia do espaço da solidão, percebe-se que o deserto árido e rochoso da Bíblia dá lugar ao eremus.

Um dos mais importantes testemunhos dessa transferência da tradição oriental do espaço da solidão foi João Cassiano (v. 360-v. 433). Suas Conferências e suas Instituições cenobíticas, escritas nas primeiras décadas do século $\mathrm{V}$, trazem para o Ocidente o exemplo dos ascetas do Oriente. Sua preferência pelo anacoretismo espiritual vivido de modo cenobítico marcou profundamente o monasticismo ocidental que passou a privilegiar em seguida a vida coletiva dos monges em detrimento da corrente eremítica. ${ }^{39}$

Uma breve apresentação quantitativa pode nos fornecer indícios de importantes mudanças qualitativas na história semântica da solidão. No total, Cassiano utiliza 15 vezes desertus, 93 eremus e 108 solitudo. Por obra, a distribuição é bastante significativa. As Instituições cenobíticas apresentam desertus 4 vezes, eremus 17 e solitudo 18; as Conferências têm 11 ocorrências de desertus, 76 de eremus e 90 de solitudo. Apesar dessa última obra ser de comprimento substancialmente maior que a outra, a conquista do deserto monástico pelo eremus é evidente.

Mais importante do que uma simples consequência da ausência do deserto árido da Bíblia nos ecossistemas ocidentais, a mudança lexical pode ser explicada por uma mudança na topografia do conceito de solidão. Como vimos, desde ao menos Isidoro de Sevilha, o termo eremus possui claramente um sentido muito próximo do significado de desertum (lugar não habitado, não cultivado e distante do tecido social urbano), mas com a vantagem de não estar ligado a uma morfologia geográfica ou ecológica exata e de remeter a um espaço supostamente virgem (isto é, livre do domínio humano). Essa mutação semântica do deserto, realizada através de um processo de metaforização do

\footnotetext{
${ }^{39}$ DRIVER, Steven David. A reconsideration of Cassian's views on the communal and solitary lives. In: BURMAN, Thomas et alii. Religion, text and society in medieval Spain and Northern Europe. Essays in honor of J. N. Hilgarth. Toronto: Pontifical Institute of Mediaeval Studies, 2002, p. 277-301.
} 
sentido concreto em direção a um sentido abstrato ocorreu mediante um processo que venho chamando de "monopolização da solidão".

Tal processo implica, grosso modo, na subtração de determinados espaços, nomeados como desertum, eremus ou solitudo, da circulação socioeconômica e política habitual e, consequentemente, no controle total desses espaços por parte dos profissionais da solidão, vale dizer, eremitas e grupos monásticos de cunho eremítico como os cartuxos, para citar apenas um exemplo. O domínio da solidão passa assim a ser o domínio do ermo, de seus frutos espirituais certamente, mas também dos bens materiais ali produzidos, das pessoas que ali circulam e habitam, em suma, das relações sociais e das riquezas, tudo sob a tutela desses importantes representantes da instituição eclesiástica que são os monges e eremitas.

Quando identifico esses agentes sociais como representantes da Igreja, não pretendo minimizar a existência de forças dissidentes dentre eles, muito pelo contrário. Pretendo, na verdade, explicitar que o domínio do espaço da solidão depende, em grande medida, da normalização da vida religiosa monástica. Nesse sentido, não é um acaso que seja justamente no mesmo período e por meio de autores como João Cassiano e Bento de Núrsia (c. 480c. 547) que aconteça simultaneamente a entrada fulgurante do termo eremus e a redação das primeiras regras monásticas propriamente latinas. Um e outro fenômeno fazem parte de um esforço normativo que tenta, por um lado, excluir formas solitárias de monasticismo (sarabaítas e girovagos, por exemplo $)^{40}$ em prol do cenobitismo e, por outro, estabelecer o monopólio do espaço de solidão por meio da articulação ermo-eremita.

O eremus será assim progressivamente investido por um conteúdo moral (lugar bom ou ruim, terrível ou agradável) e espiritual (ligado à penitência e à redenção), elementos, como vimos, presentes nas retóricas bíblica e clássica do lugar de solidão. Aos poucos (sobretudo entre os séculos XI e XII), esse termo toma lugar na economia da salvação com um duplo sentido: aquele das trocas de bens materiais (principalmente fundiários, no que concerne aos diplomas que atestam a circulação e a proteção das terras ermas) e o trânsito da presença de Deus nos lugares, nas coisas e nas pessoas

\footnotetext{
${ }^{40}$ Ver as definições apresentadas no capítulo 1 da Regra beneditina.
} 
associados ao eremus. A partir do controle deste lugar de solidão, a Igreja irá exercer seu papel mediador entre o mundo terrestre e o mundo espiritual, organizando (ou tentando organizar) as relações entre os homens. A solidão participa, assim, do funcionamento do sistema eclesial que se pretende ao mesmo tempo presente no mundo e fora dele.

Quão longe estamos daquela solidão entendida como um deserto-floresta onde não há ninguém, pois situado fora do mundo e da hierarquia social; um lugar onde poder e laços sociais dariam lugar a contemplação solitária e incessante de Deus (ver acima). Percebemos agora que falar em solidão na Idade Média não nos leva a tratar de indivíduos isolados do convívio humano, pelo contrário. Quando os autores medievais escrevem sobre a solidão eles buscam, antes de tudo, falar das diferentes possibilidades de se viver em comunidade. Por isso, para eles, falar em solidão significa tratar de modalidades de laços sociais. Assim, ao final deste estudo da polissemia da solidão medieval podemos compreender melhor o sentido social profundamente associado ao termo.

\section{Referências bibliográficas}

A bibliografia aqui apresentada resume-se apenas às obras citadas em notas de rodapé.

BASCHET, Jérôme. Âme et corps dans l'Occident médiéval: une dualité dynamique, entre pluralité et dualisme. Archives de sciences sociales des religions, n. 112. Paris: CNRS, 2000, p. 5-30.

BRÄNDLE, Rudolf Jean Chrysostome (349-407). "Saint Jean Bouche d'Or". Christianisme et politique au IVe siècle. Paris: Cerf, 2003 [1999].

CASTANHO, Gabriel de Carvalho Godoy. Isolement, communauté et société. Sémantique de la solitude en contexte monastique latin (v. 1080-v. 1150). Tese de doutorado, Histoire et Civilisations, CEIFR, EHESS, 2013.

Cross Database Searchtool. Turnhout: Brepols, 2013.

CURTIUS, Ernst Robert. A literatura europeia e a Idade Média latina. Tradução. São Paulo : Hucitec/Edusp, 1996 [1948].

DELAPLACE, Christine. Aux origines du "désert" en Occident. Érémitisme et premières fondations monastiques en Gaule et en Italie aux Ve-VIe siècles après Jésus-Christ. In: BRUNET, Serge; JULIA, Dominique; LEMAITRE, Nicole (org.). Montagnes sacrées d'Europe. Actes du colloque "Religion et montagnes". Tarbes, 30 mai-2 juin 2002. Paris: Publications de la Sorbonne, 2005, p. 217-226.

DESCOLA, Philippe. Par-delà nature et culture. Paris: Gallimard, 2005.

DESPY, Georges. A propos de "déserts" dans les campagnes au XII e siècle. In: MORNET, Elisabeth (org.). Campagnes médiévales: l'homme et son espace. Études offertes à Robert Fossier. Paris: Publications de la Sorbonne, 1995, p. 549-562. 
rev. hist. (São Paulo), n. 173, p. 115-139, jul.-dez., 2015 http://dx.doi.org/10.11606/issn.2316-9141.rh.2015.105633
Gabriel de C. G. Castanho

A polissemia (social) do deserto: uma história do tópos histórico e historiográfico da solidão monástica no contexto latino medieval

DRIVER, Steven David. A reconsideration of Cassian's views on the communal and solitary lives. In: BURMAN, Thomas et alii. Religion, text and society in medieval Spain and Northern Europe. Essays in honor of J. N. Hilgarth. Toronto: Pontifical institute of mediaeval studies, 2002, p. 277-301.

EDWARDS, Mark. Locus horridus and locus amoenus. In: HARDIE, Philip \& WHITBY, Mary (ed.). Homo viator. Classical essays for J. Bramble. Bristol/Oak Park: Bristol Classical Press/Borchazy-Carducci, 1987, p. 267-276.

FISCHER, Bonifatio; GRIBOMONT, Johanne; WEBER, Robertus et alii (ed.). Biblia sacra juxta vulgatam versionem. Stuttgard: Württembergische Bibelanstalt, 1969.

FONTANIER, P. Les figures du discours [GENETTE, Gérard. Introdução.]. Paris: Flammarion, 1977 [1821].

FRANCESCHI, Catherine. Du mot paysage et de ses équivalents dans cinq langues européennes.In:COLLOT,Michel(org.).Lesenjeux du paysage. Bruxelas:Ousia, 1997, p. 75-111.

GIOANNI, Stéphane. "Être véritablement moine": les représentations de l'identité ascétique dans la pastorale lérinienne ( $\mathrm{V}^{\mathrm{e}}-\mathrm{VI}^{\mathrm{e}}$ siècles). In: CODOU, Y. $\mathcal{E}$ LAUWERS, M. (org.). Lérins, une île sainte de l'Antiquité au Moyen Âge. (Collection d'Études Médiévales de Nice, 9) Turnhout: Brepols, 2009, p. 141-166.

GREGOIRE, Réginald. La foresta come esperienza religiosa. In: L'ambiente vegetale nell'alto Medioevo. Spoleto: Centro italiano di studi sull'alto Medievo, 1990, p. 663-707.

GUIZARD-DUCHAMP, Fabrice. Les espaces du sauvage dans le monde franc: réalités et représentations. In: XXXVII ${ }^{\mathrm{e}}$ CONGRES DE LA SHMES, 2006. Construction de l'espace au Moyen Âge: pratiques et représentations. Paris: Publications de la Sorbonne, 2007, p. 117-129.

Les terres du sauvage dans le monde franc: IVe-IXe siècle. Rennes: PUR, 2009.

ISIDORO DE SEVILHA. De differentiis uerborum ou Differentiarum siue de proprietate sermonum libri duo. In: CODONER, Carmen (ed.). Isidoro de Sevilla, Diferencias, livro I. Paris: Les Belles Lettres, 1992.

JERÔNIMO. Epístola 22 a Eustochium. In: HILBERG, Isidorus (ed.). Epistolae, I. (Corpus Scriptorium Ecclesiasticorum Latinorum - CSEL, 54) Viena: Verl. der Österreichischen Akademie der Wissenschaften, 1996 [1910].

JOÃO CRISÓSTOMO. Homiliae IX de Poenitentia. In: MIGNE, Jacques-Paul (ed.). Patrologiae cursus completus: series graeca. Turnhout: Brepols, 1862, p. 49.

Homiliae L. In: MIGNE, Jacques-Paul (ed.). Patrologiae cursus completus: series graeca. Turnhout: Brepols, 1862, p. 58.

LE GOFF, Jacques. Le désert-forêt dans l'Occident médiéval. In: Idem. L'imaginaire médiéval. Paris: Gallimard, 1991 [1985], p. 59-75.

McGRAW John. God and the problem of loneliness. Religious Studies, n. 28, 3. Londres: Cambridge University Press, 1992, p. 319-346.

ORDERICO VITAL. História eclesiástica. In: CHIBNALL, Marjorie. The ecclesiatical history of orderic vitalis. Oxford: Carendon Press, 1972.

PRINZ, Friedrich. Frühes Mönchtum im Frankenreich: Kultur und Gesellschaft in Gallien, den Rheinlanden und Bayern am Beispiel der monastischen Entwicklung (4. bis 8. Jahrhundert). Munique/Viena: R. Oldenbourg, 1965. 
Gabriel de C. G. Castanho

A polissemia (social) do deserto: uma história do tópos histórico e historiográfico da solidão monástica no contexto latino medieval

QUINTILIANO. Institutio Oratoria. In: RUSSELL, Donald (ed., trad. e notas). The orator's education. (The Loeb Classical Library, 126) Cambridge/Londres: Harvard University Press, 2002.

SANTSCHI, Catherine. La solitude des ermites. Enquête en milieu alpin. Médiévales, n. 28. Saint-Denis: Centre de recherche de l'Université de Paris VIII, 1995, p. 25-40.

SCHLAPBACH, K. The pleasance, solitude and literary production. The transformation of the locus amoenus in late Antiquity. In: Jahrbuch für Antike und Christentum, n. 50. Münster: Aschendorf, 2007, p. 34-50.

SCHROEDER, Nicolas. In locis vaste solitudinis. Représenter l'environnement au haut Moyen Âge: l'exemple de la Haute Ardenne (Belgique) au VII siècle. Le Moyen Âge, n. 116. Bruxelas: De Boeck, 2010, p. 9-35 (DOI: 10.3917/rma.161.0009).

THOSS, Dagmar. Studien zum locus amoenus im Mittelalter. Viena: Braumüller, 1972.

VON DER NAHMER, Dieter. Die Klostergründung "in solitudine" ein unbrauchbarer hagiographischer Topos? In: Hessisches Jahrbuch für Landesgeschichte, n. 22. Marburg: Arbeitsgemeinschaft der Historischen Kommissionen in Darmstad, 1972, p. 90-111.

WICKHAM, Chris. European forests in the early Middle Ages: Landscape and land clearance. L'ambiente vegetale nell'alto medioevo, t. 2. Spoleto: Centro italiano di studi sull'alto Medievo, 1990, p. 479-548.

Recebido: 13/04/2015 - Aprovado: 25/09/2015 
